1

2

3

4

5

6

7

8

9

10

11

12

13

14

15

16

\section{Wearing a Mint-Scented Face Mask Reduces Appetite}

\author{
Yuki Miyazaki ${ }^{1}$ and Jun I. Kawahara ${ }^{2}$ \\ ${ }^{1}$ Department of Psychology, Fukuyama University \\ ${ }^{2}$ Graduate School of Letters, Hokkaido University
}

\begin{abstract}
Author Note
Yuki Miyazaki (iD https://orcid.org/0000-0003-4790-4368

Jun I. Kawahara (iD https://orcid.org/0000-0002-4096-3923

Correspondence concerning this article should be addressed to Yuki Miyazaki, Department of Psychology, Fukuyama University, Sanzo 1, Gakuen-cho, Fukuyama, Hiroshima, 7290292, Japan. Email: y38@fukuyama-u.ac.jp
\end{abstract}




\section{Abstract}

Previous studies have shown that mint scents reduce chocolate craving. However, two questions remain: whether the effect is an artifact of demand characteristics in which participants were aware that the study aimed to examine the effect of mint scent, and whether mint scent reduces appetite for foods generally other than chocolate. The present study took advantage of the fact that wearing face masks in public is becoming a standard norm because of the COVID-19 pandemic, to manipulate scent presentation to participants. We investigated the potential application of mint-scented masks for appetite control. Participants who were deceived that wearing masks were for consumer testing to eliminate demand characteristics rated their perceived wanting to eat for a variety of food images that had been preliminarily rated for perceived wanting while wearing a mint-scented mask (or an unscented control mask). The results showed that wearing a mint-scented compared to an unscented mask reduced perceived wanting for foods regardless of base wanting. The results demonstrate a novel potential application of mint-scented masks, namely appetite control, and replicates and extends the generalizability of past findings by excluding artifacts of demand characteristics.

Keywords: face mask, mint scent, appetite, wanting, COVID-19

(1)

\section{Significance Statement}

Although effective in preventing the spread of COVID-19, wearing a face mask has negative side-effects on cognition (e.g., reading a mask wearer's facial expressions is difficult). Previous studies on mask-wearing during the COVID-19 era have only highlighted negative side-effects. The present study is the first to report a positive side-effect of maskwearing on cognition; namely, wearing a mint-scented face mask regulates appetite.

Furthermore, a scented mask has the advantage of being able to present the scent only to the wearer compared to other scent-presenting tools (e.g., aroma diffusers); that is, the scented mask provides the wearer with a portable personal scent space. Moreover, this tool can be 
43 adopted easily because of commercially availability of low-cost products and can be used

44 outdoors. The present study is also pioneering research proposing a novel scent-presentation

45 method because scented masks have never before been examined in investigations of the 46 psychological effects of scents.

47

48 
Wearing face masks in public is becoming a standard norm in many countries because of the COVID-19 pandemic (Institute for Health Metrics and Evaluation, 2021). The market for face masks grew rapidly in 2020 , and different types of face mask products have become available, with variations including colors, fabrics, shapes, and filtering capabilities. Some products are equipped with a scenting function using microcapsules containing scents woven into the mask's fabric, which can be generated by tapping the surface of the fabric. Wearers can enjoy the scent throughout the day by re-generating via tapping, even though the subjective intensity of the scents is attenuated by adaptation. Considering that scents affect cognition and behavior, and have been applied in various contexts (Morrin, 2010; Spence, 2021a, 2021b), scented masks also have potential real-world applications. In addition, scented masks have the advantage of presenting the scent only to the wearer, compared to other scent-presenting tools (e.g., aroma diffusers). This study examined a potential application of mint-scented masks.

Scents affect appetite (Firmin et al., 2016; Kemps \& Tiggemann, 2007, 2013; Kemps et al., 2012). For example, a study found that mint scents reduce chocolate cravings (Firmin et al., 2016). In the study, participants rated their craving to four images of chocolates while being exposed to a mint (strictly speaking, citramint combining citrus and mint) essential oil presented in a petri dish. Cravings for the chocolate images under presentation of the mint scent were lower compared to a control condition in which no scenting substance was provided. Other researchers have demonstrated a similar reduction of chocolate cravings; presentation of a nonfood scent (jasmine) reduced chocolate cravings compared to that of a food scent (green apple) and non-scent (Kemps et al., 2012). Taken together, the presentation of mint and/or non-food scents reduce chocolate cravings.

However, two questions remain (Firmin et al., 2016; Kemps et al., 2012). First, participants might have become aware of the study purpose because manipulation of scent presentation was implemented in a within-participants design. Moreover, participants were required to smell the scent presented in a petri dish or vial after observing chocolate images, 


\section{Participants}

\section{Participants}

and then rate their chocolate craving intensity. Therefore, their results might have involved experimental demand characteristics that made participants explicitly aware of the manipulation purpose of the scent, thus prompting them to respond in an expected way. Second, the generalizability of these findings is unclear. These studies focused only on chocolate cravings.

This is because they tackled control of cravings for chocolate foods; however, it was unclear whether appetite for other foods could also be reduced by these scents. It is important to understand whether presentation of certain scents can be effective in curbing the appetite for foods generally as well as chocolate, which could be applied to curb overeating. We chose a scented mask to manipulate scent because it is an optimal medium to deliver a scent while preventing participants' awareness that the scent was the critical factor in the ostensible context of customer testing of the comfortableness of breathing mask products.

The present study aimed to test the reduction effect of wearing a mint-scented mask on appetite. Given that mint and/or non-food scents (i.e., mint, like jasmine, is not a food but a herb) reduce the craving for chocolate (Firmin et al., 2016; Kemps et al., 2012), a similar reduction effect should occur with the mint scent. Therefore, we predicted that appetite should be decreased when participants wore a mint-scented mask compared to an unscented mask. To answer the two questions of whether the effect of participants' awareness of the manipulation purpose of scent was critical to the reduction effect of mint scent on appetite and whether the effect is not limited to appetite for chocolates, a post-experimental manipulation check for awareness of the study purpose was administered, and then we used a variety of food images that had been preliminarily rated for level of perceived desire to eat.

\section{Method}

We estimated that the reduction effect of mint scent on appetite was large (Cohen's $d>$ 0.80) based on a previous study (Firmin et al., 2016) and planned to recruit at least 12 participants (statistical test: paired $t$-tests (one-tailed), $\alpha=.05,1-\beta=.80$ ). This size was 
101

102

103

104

105

106

107

108

109

110

111

112

113

114

115

116

117

118

119

120

121

122

123

124

125

126

calculated using G*Power 3 (Faul et al., 2007). However, based on our experience, we believed that a sample size of 12 was insufficient. Thus, we decided to collect 24 participants based on Firmin et al.'s study. Fifty-two volunteers ( 27 females and 25 males; $M_{\text {age }}=19.8$ years) participated. However, data from 28 (14 females) were excluded from the main analysis because they answered that they became aware of the purpose of the study during the experiment. Data from these 28 participants were handled with a subsidiary analysis. Further participants (who did not become aware of the purpose) were added until the sample size reached 24. All participants provided informed consent and participated for pay. This research project was approved by the research ethics committee of the last author's institution.

\section{Design}

The independent variable was mask-scent (within-participants factor: mint-scented and unscented mask conditions). The order of the conditions was counterbalanced among participants. The dependent variable was perceived wanting for food images measured from 1 (do not want to eat) to 100 (want to eat) via a linear scale.

\section{Apparatus}

The control of experimental stimuli and recording of participants' responses were performed by a script using the Psychophysics Toolbox (Kleiner et al., 2007) in MATLAB on a PC (ALIENWARE AURORA, Dell). The stimuli were presented on an LCD (XL2411Z, Benq; $1920 \times 1080$ pixels) at a viewing distance of approximately $57 \mathrm{~cm}$. The participants were instructed to maintain this distance, although a chinrest was not used. Participants' responses were acquired through an optical mouse.

\section{Food stimuli}

The stimuli were drawn from a database (Kobayashi, Otake, \& Inoue, 2019) that contained a variety of food images (mainly Japanese food images; main and side dishes, fruits, and sweets; $N=369$ ). All images in the database had been rated for perceived wanting on a 9point scale (1: do not want to eat; 9: want to eat). The $M(S D)$ score of perceived wanting of 
127

128

129

130

131

132

134

135

136

137

138

139

140

141

142

143

144

145

146

147

148

149

150

151

152

these images was $5.48(0.63)$. We selected 90 images from the database: 30 images with low scores $(<4.86)$ were selected, another 30 with average scores $(5.41-5.58)$ were selected, and

the remaining 30 had high scores (>6.11). Detailed information of the selected images is shown at OSF (https://osf.io/5rzhw/?view only=13765c0bc53546d381c6e4b2f87cfc52).

\section{Procedure}

Upon arrival at the laboratory's waiting area, participants were instructed that they would engage in two types of experiments simultaneously: one was to rate perceived wanting for 90 food images and the other was a usability test of two face mask products. They were told to rate 45 of 90 images while wearing one mask and the remaining 45 images rate while wearing the other mask. After these instructions, they wore a mint-scented face mask or an unscented face mask (Cho-kaitek迥 [ultra-comfortable] mask, either pleats-mint type [scented] or pleats-regular type [unscented], Unicharm Corporation) and waited for two minutes with the face masks on to adapt to their smell and size. The two masks were identical, except for the presence or absence of the scent. Participants moved from the waiting area to the experimental booth after the 2minute waiting period. Before starting the rating task, participants were instructed to return to the waiting area after completing the 45 ratings to complete the usability form regarding the face mask they were currently wearing. In addition, participants were told not to remove the mask during the rating task to maintain identical wearing conditions for the usability test.

The experimental procedure is illustrated in Figure 1A. In the first half of the rating task, participants evaluated the perceived wanting of each of 45 randomly selected food images while wearing a mint-scented or unscented mask. The 45 images consisted of 15 images randomly chosen from each of the low, average, and high perceived wanting scores images. A food image (color JPEG; landscape image size was $13.3^{\circ} \times 8.9-10.6^{\circ}$ and portrait image size was $8.8-9.4^{\circ} \times 13.3^{\circ}$ ) was presented in the center of the screen on a white background square $\left(13.8^{\circ} \times 13.8^{\circ}\right)$. A linear scale was concurrently presented below the food image (Figure 1B). Participants reported perceived wanting of the image by a mouse click on the scale at their 
leisure. After the mouse click, the next food image appeared, preceded by a brief blank screen. After completing a mock questionnaire consisting of five items (ease of breathing, fit, comfort, ear pain, and protection from pollen and virus) asking about wearing the mask on a 7point scale, they changed face masks (i.e., they wore an unscented mask if they wore a mintscented mask in the first half-session, and vice versa). The scores of the mock questionnaire were not used because it was designed to improve the credibility of the usability test for the mask. Two minutes after switching masks, participants returned to the experimental booth. They then evaluated the remaining 45 food images. The procedures and instructions for the second half of the session were identical to those of the first.

Finally, participants were informed of the actual study purpose after finishing the usability test for the worn mask during the second half of the session. As a manipulation check, they were asked to answer whether and why (if they were aware) they became aware of the study purpose during the experiment. During the debriefing, we carefully informed participants of the need for deception in this study. Permission to use their data was then obtained from all participants.

\section{Results}

All analyses were conducted by using jamovi (The jamovi project, 2021). Wearing a mint-scented mask reduced perceived wanting for food images. The mean scores of perceived wanting in the mint-scented mask condition $(M=53.0, S D=10.1)$ were lower than those in the unscented mask condition $(M=55.4, S D=9.8), t(23)=-2.09, p=.024$, Cohen's $d=0.43$. The subsidiary analysis indicated that the difference between the mint-scented mask $(M=55.4, S D$ $=11.5)$ and unscented mask conditions $(M=55.3, S D=11.1)$ was not significant in participants who became aware of the study purpose, $t(27)=0.06, p=.525$, Cohen's $d=0.01$.

We conducted an additional analysis to investigate whether the reduction effect of wearing a mint-scented mask differed from the base wanting of low, average, and high scores of the food images. We performed a two-way ( 2 mask-scent $\times 3$ base wanting) ANOVA for 
179 180

perceived wanting. Significant main effects were found for mask-scent: $F(2,23)=4.35, p=$ $.048, \mathrm{n}_{\mathrm{p}}^{2}=.16$, and base wanting: $F(2,46)=41.39, p<.001, \mathrm{n}_{\mathrm{p}}^{2}=.64$, although the interaction was not significant, $F(2,46)=1.28, p=.288, \eta_{p}^{2}=.05$. These results suggest that the reduction effect of wearing a mint-scented mask on perceived wanting for food occurred regardless of base wanting of the food images.

\section{Discussion}

We demonstrated that wearing a mint-scented mask reduced appetite for a variety of foods. This reduction effect was not observed when participants became aware of the experiment's purpose. Hence, usage to control appetite is not effective if a mask wearer knows the association between mint-scent and appetite. In an additional analysis, we found that this reduction effect occurred regardless of the baseline level of perceived wanting to eat for the food images. In sum, these results replicated previous findings that chocolate craving is reduced by presentation of mint and/or non-food scents (Firmin et al., 2016; Kemps et al., 2012), while excluding artifacts of demand characteristics, and generalizing the results (i.e., mint-scent reduces appetite for various foods).

A limitation of the study was that only one scent, namely mint, was examined. This limitation was unavoidable because we used the same series of face mask products to control for other factors (e.g., mask shape and material), except for the mask-scent. We need to replicate the current findings by using face mask products with other scents because face masks with non-food scents such as lavender are also commercially available. Relatedly, Firmin et al. (2016) reported that presentation of a vanilla scent increased craving for chocolate. Other researchers have demonstrated that presentation of certain scents promotes food preferences (Yamada et al., 2014). Future research should also study the stimulating effect of wearing a scented mask on appetite.

Mint-scented face masks were originally designed to relieve nasal discomfort caused by hay fever and cold. In the present study, we provide a new potential application: appetite control. 
205 Scented masks provide wearers with a portable personal scent space. This scent-presenting

206 tool can be adopted easily because commercially available low-cost products can be used

207 outdoors and applied to the wearer only, although the variety of scents is smaller than that of

208 essential oil products. Previous studies have highlighted only negative side-effects of mask-

209 wearing on cognition (e.g., difficulty in reading facial expressions; Carbon, 2020). The present

210 study is the first to report a positive side-effect of mask-wearing. It would be worthwhile to

211 further examine the effect of wearing a mint-scented mask on appetite in various daily situations

212 (e.g., controlling portion size in restaurants), considering that we will still be required to wear

213 masks in public for some time after full vaccination (Yang et al., 2021).

Ethics approval and consent to participate

This research project was approved by the research ethics committee of the last

218 author's institution. All participants provided informed consent.

219 Availability of data and material

Data and additional online materials are openly available on the project's Open Science

221 Framework page (https://osf.io/5rzhw/?view only=13765c0bc53546d381c6e4b2f87cfc52).

\section{$222 \quad$ Funding}

This study was funded by the Unicharm Corporation. The un/scented face masks used

224 in this study were commercial products of Unicharm Corporation.

$225 \quad$ Competing interests

The authors declare that they have no competing interests.

\section{Acknowledgements}

We would like to thank Kanto Fujisaki for his help with data collection and Masanori

229 Kobayashi for providing the data for the food image database.

\section{Authors' Contributions}


232 collection and data analysis were performed by Y. M. Y. M. drafted the manuscript, and J. I. K.

233 provided critical revisions. All authors approved the final version of the manuscript for

234 submission. 


\section{References}

Carbon, C.-C. (2020). Wearing face masks strongly confuses counterparts in reading $\begin{array}{lllll}\text { emotions. } & \text { Frontiers } & \text { in } & \text { Psychology, } & 11,\end{array}$ https://doi.org/10.3389/fpsyg.2020.566886

Faul, F., Erdfelder, E., Lang, A.-G., \& Buchner, A. (2007). G*Power 3: A flexible statistical power analysis program for the social, behavioral, and biomedical sciences. Behavior Research Methods, 39(2), 175-191. https://doi.org/10.3758/bf03193146

Firmin, M. W., Gillette, A. L., Hobbs, T. E., \& Wu, D. (2016). Effects of olfactory sense on chocolate craving. Appetite, 105, 700-704. https://doi.org/10.1016/j.appet.2016.07.004

Institute for Health Metrics and Evaluation. (2021, May 27). COVID-19 Maps of Mask Use. Institute for Health Metrics and Evaluation. http://www.healthdata.org/acting-data/covid19-maps-mask-use

Kemps, E., \& Tiggemann, M. (2007). Modality-specific imagery reduces cravings for food: An application of the elaborated intrusion theory of desire to food craving. Journal of Experimental Psychology: Applied, 13(2), 95-104. https://doi.org/10.1037/1076898X.13.2.95

Kemps, E., \& Tiggemann, M. (2013). Olfactory stimulation curbs food cravings. Addictive Behaviors, 38(2), 1550-1554. https://doi.org/10.1016/j.addbeh.2012.06.001

Kemps, E., Tiggemann, M., \& Bettany, S. (2012). Non-food odorants reduce chocolate cravings. Appetite, 58(3), 1087-1090. https://doi.org/10.1016/j.appet.2012.03.002

Kleiner, M., Brainard, D., Pelli, D., Ingling, A., Murray, R., \& Broussard, C. (2007). What is new in psychtoolbox 3. Perception, 36(14), 1-16.

Kobayashi, M., Otake, K., \& Inoue, K. (2019, November 30). Syokumotsu gazo hyouka detabesu no sakusei: nihonshoku wo chushin ni [Development of a food image database: Focusing on Japanese foods] [Poster presentation]. The 38th Annual Meeting of the Japanese Psychonomic Society, Kobe, Japan. 
262 Morrin, M. (2010). Scent marketing: An overview. In A. Krishna (Ed.), Sensory marketing: Research on the sensuality of products (pp. 75-86). Routledge/Taylor \& Francis Group.

264 265

Spence, C. (2021a). Scent in the context of live performance. I-Perception, 12(1), 2041669520985537. https://doi.org/10.1177/2041669520985537

Spence, C. (2021b). The scent of attraction and the smell of success: Crossmodal influences on person perception. Cognitive Research: Principles and Implications, 6(1), 46. https://doi.org/10.1186/s41235-021-00311-3

The jamovi project (2021). jamovi. (Version 1.6) [Computer Software]. Retrieved from https://www.jamovi.org.

Yamada, Y., Sasaki, K., Kunieda, S., \& Wada, Y. (2014). Scents boost preference for novel fruits. Appetite, 81, 102-107. https://doi.org/10.1016/j.appet.2014.06.006

Yang, J., Marziano, V., Deng, X., Guzzetta, G., Zhang, J., Trentini, F., Cai, J., Poletti, P., Zheng, W., Wang, W., Wu, Q., Zhao, Z., Dong, K., Zhong, G., Viboud, C., Merler, S., Ajelli, M., \& Yu, H. (2021). Despite vaccination, China needs non-pharmaceutical interventions to prevent widespread outbreaks of COVID-19 in 2021. Nature Human Behaviour, 5(8), 1009-1020. https://doi.org/10.1038/s41562-021-01155-z 


\section{$279 \quad$ Figure 1}

280 Experimental procedure and experimental task.

(A) Procedure

\begin{tabular}{|c|c|}
\hline \multicolumn{2}{|c|}{ Instruction } \\
\hline $\begin{array}{l}\text { Wearing a mint- } \\
\text { scented mask }\end{array}$ & $\begin{array}{c}\text { Wearing an } \\
\text { unscented mask }\end{array}$ \\
\hline $\begin{array}{l}\text { The first half } \\
\text { (45 randomly s }\end{array}$ & $\begin{array}{l}\text { e rating task } \\
d \text { food images) }\end{array}$ \\
\hline $\begin{array}{r}\text { The usability te } \\
\text { during }\end{array}$ & $\begin{array}{ll} & \\
\text { the worn mask } \\
\text { rst half }\end{array}$ \\
\hline $\begin{array}{c}\text { Wearing an } \\
\text { unscented mask }\end{array}$ & $\begin{array}{l}\text { Wearing a mint- } \\
\text { scented mask }\end{array}$ \\
\hline $\begin{array}{l}\text { The second h } \\
\text { (the remainin }\end{array}$ & $\begin{array}{l}\text { the rating task } \\
\text { food images) }\end{array}$ \\
\hline $\begin{array}{l}\text { The usability te } \\
\text { during th }\end{array}$ & $\begin{array}{l}\text { the worn mask } \\
\text { ond half }\end{array}$ \\
\hline Manipu & check \\
\hline 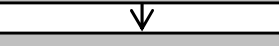 & $\downarrow$ \\
\hline & \\
\hline
\end{tabular}

(B) Rating task

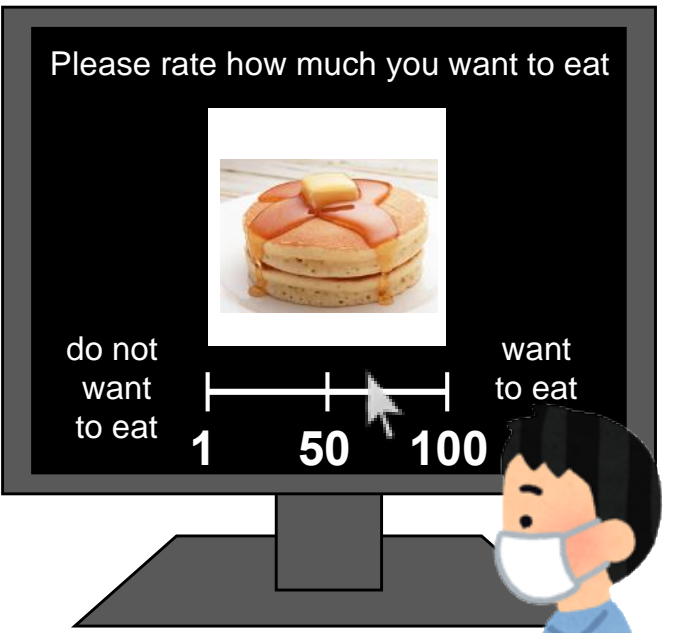


283 Figure 2

284 Means of the perceived wanting of foods in the mint-scented and unscented mask conditions.

285 Error bars represent standard error. ${ }^{*} p<.05$

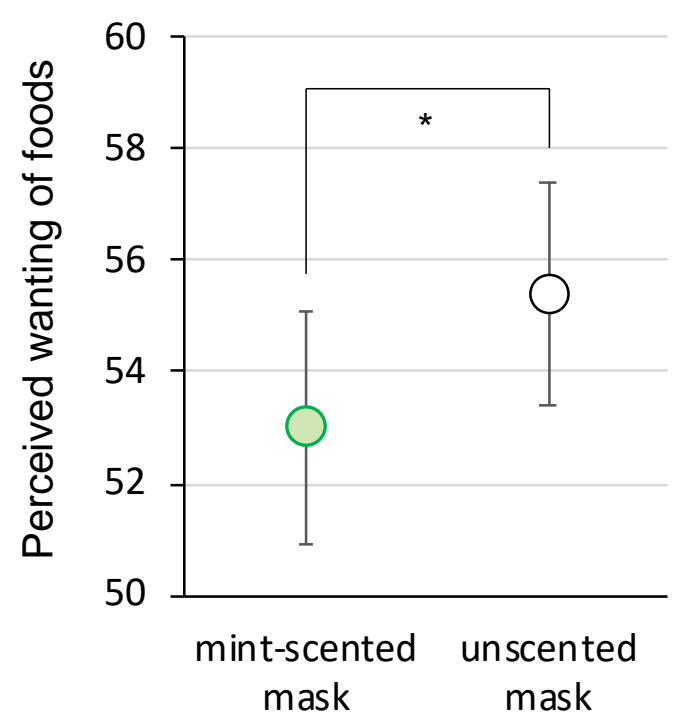

